\title{
The use of the reversed facial flap in midface reconstruction following advanced sinonasal malignancies
}

\author{
Viorel Zainea ${ }^{1,2}$, Octavian Ceachir ${ }^{2}$, Irina Ioniță2 ${ }^{2}$ Cătălina Pietroșanu ${ }^{1,2}$, Carmen Drăghici ${ }^{1}$, \\ Cristina Zamfir ${ }^{1}$, Răzvan Hainăroșie ${ }^{1,2}$
}

'Institiute of Phonoaudiology and Functional ENT Surgery "Prof Dr Dorin Hociota", Bucharest, Romania

"University of Medicine and Pharmacy "Carol Davila", Bucharest, Romania

\section{ABSTRACT}

The objectives of the study: Advanced or recurrent sinonasal malignancies sometimes need, besides an ablative step, a reconstructive step. If this occurs, the reconstructive step may require advanced knowledge of reconstructive surgery because of the complex remnant defects after ablation.

The methodology: The authors present a surgical reconstructive solution that can be used in cases of advanced sino nasal tumors which associate the destruction of the malar region. This requires a midfacial flap which will provide a solid support for the paramedial forehead flap.

Conclusions: The use of the reversed midfacial flap is an original method that can provide a good mechanical support for any reconstructive flap in the midfacial region.

Keyw ords: sino nasal malignancies, reconstruction, flap

\section{INTRODUCTION}

Advanced or recurrent sino nasal tumors require an ablative step followed preferably during the same surgical intervention by a reconstructive step [1]. Despite the advancement of the endoscopic surgical techniques, we believe that for advanced sino nasal malignancies the combined approach (endoscopic and external approach) is still the gold standard, considering that the main purpose is the complete removal of the tumor [2]. If that is not possible, it is preferable to remove the entire mass that can be resected, rather than perform a debulking procedure[3]. In our experience we have encountered complex cases of sino nasal malignancies with extensive destruction at the level of the mid facial region. The challenge of the reconstructive step in the midfacial defect produced by advanced or recurrent sino nasal malignancies is the complex defects that involve the bone of the malar region and the dermal and subdermal structures. In order to achieve a good esthetic result after reconstruction a bony support is
Corresponding author:

Octavian Ceachir, MD

21 Mihail Cioranu Str., District 5,

Bucharest, 050751

E-mail: octavianceachir@gmail.com

Copyright (c) Celsius Publishing House 
required. The problem in sinonasal malignancies is that the bone is affected or even destroyed by the tumor. We had to choose another surgical solution in order to achieve the support for the reconstructive flap. We used a reversed midfacial flap in order to achieve the support for the paramedian forehead flap.

Radiotherapy is recommended following surgery [4], especially considering that in the facial area the safety margins can not be too extensive. Chemotherapy remains an option for cases that have a poor evolution, but the surgeon must always bare in mind that there are studies which show that induction chemotherapy does not alter the prognosis significantly [5].

\section{MATERIALS AND METHODS}

We selected patients with advanced or recurrent sino nasal malignancies with destruction of the malar region (figures 1, 2).

During the same surgical intervention we performed both the ablative step and the reconstructive step. We used a revesed flap in order to achieve the support. The final reconstruction was made using a paramedian forehead flap. The first step of the surgery was the ablation of the tumor. This was done using a combined approach (combined endoscopic and external approach). For the external approach we mainly used the lateral rhinotomy or the trans vestibuloantral corridor. After the tumor was removed, we drilled the bony surface that came into contact with the tumor. The second step of the surgery is the reconstructive one. We reconstructed the soft structures defect located in the mid facial region using the paramedian forehead flap. The paramedian forehead flap has a good blood supply provided by the supratrochlear and supraorbital arteries [6]. In the midfacial region the main reconstructive problem is the condition of the bony support for the paramedian forehead flap. If the bony support is missing, the forehead flap is not able to provide a proper reconstruciton of the midfacial region. In order to provide a good support for the paramedian forehead flap we developed a reversed flap harvested form the lateral part of the midfacial region. We harvested the flap from the lateral part of the midfacial region. The insertion of the eliptical flap will be located $1 \mathrm{~cm}$ before the lateral area of the post ablative defect (figure 3). We then reversed the flap 180 degrees, and the tip of the flap was sutured in the medial area of the post ablative defect (figure 4). After the complete suture of the midfacial reversed flap, we started preparing the paramedial forehead vascularized

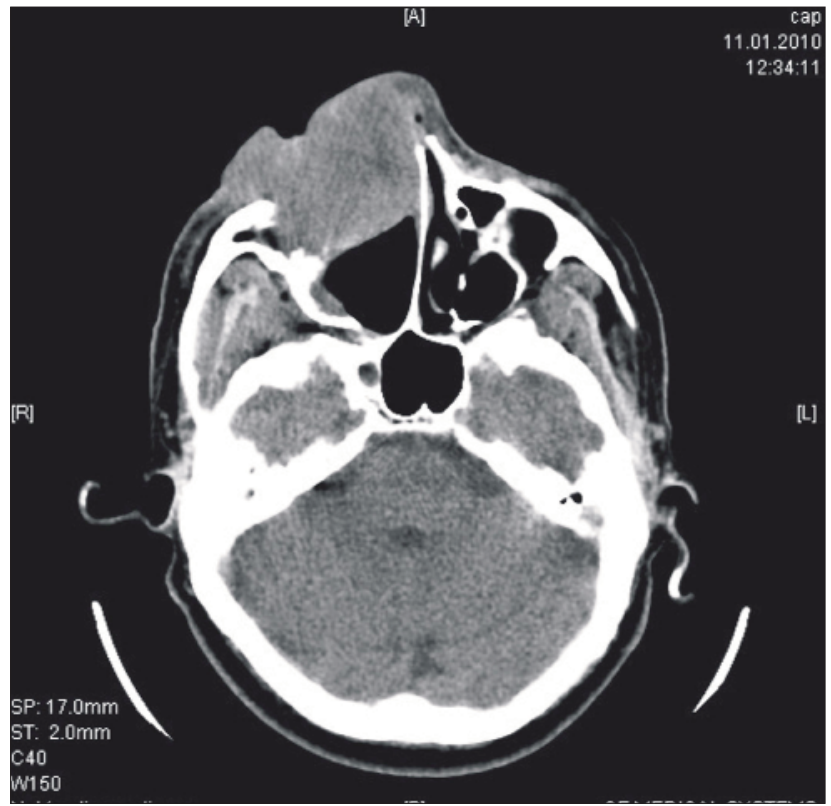

Figure 1 - Recurrent sino nasal tumor destroying the malar region and the right part of the nasal pyramid

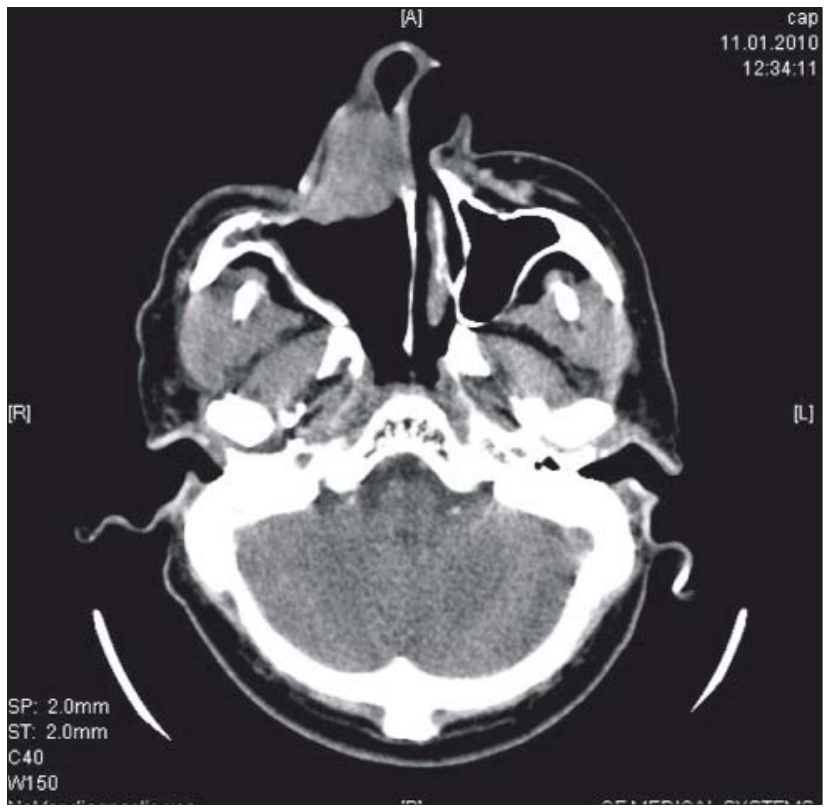

Figure 2 - Recurrent sino nasal tumor destroying the malar region and the right part of the nasal pyramid

flap (figure 5). We rotated the paramedian flap and closed the defect using the mechanical support of the midfacial revesed flap. The forehead defect was closed primarily (figure 6).

\section{RESULTS AND DISCUSSIONS}

We used the midfacial reversed flap in 4 cases in order to provide the mechanical support necessary for the paramedial forehead vascularized flap. Good 
Figure 3 - Preparing the reversed flap
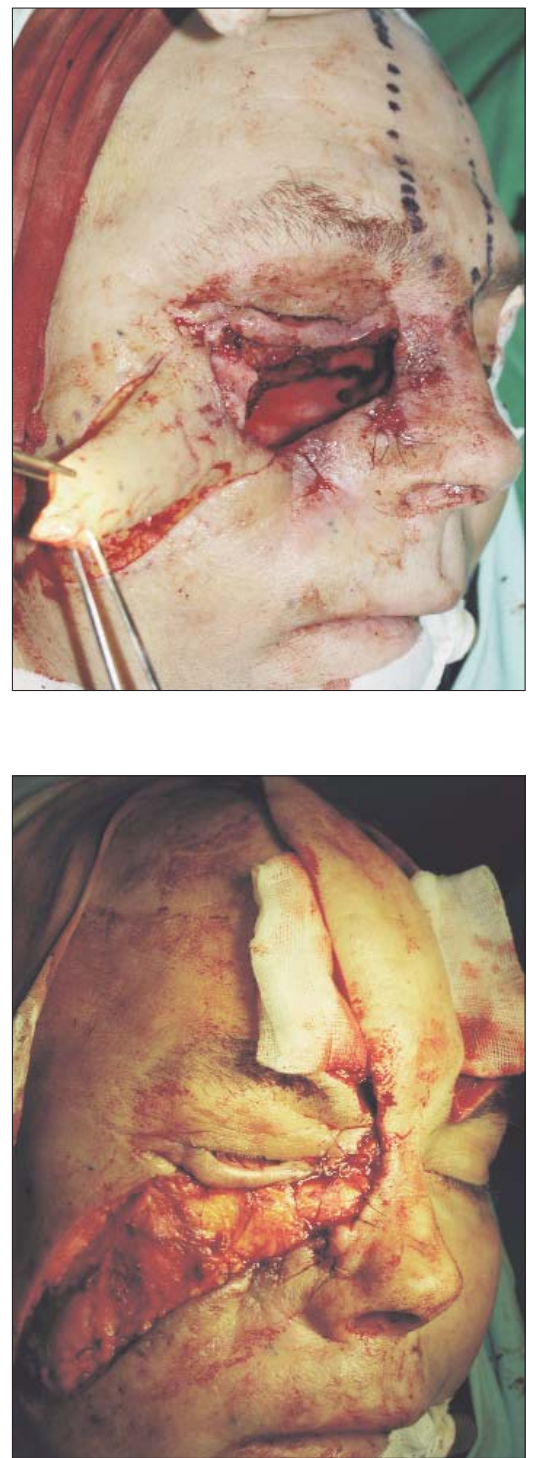

Figure 5 - Preparing the forehead flap

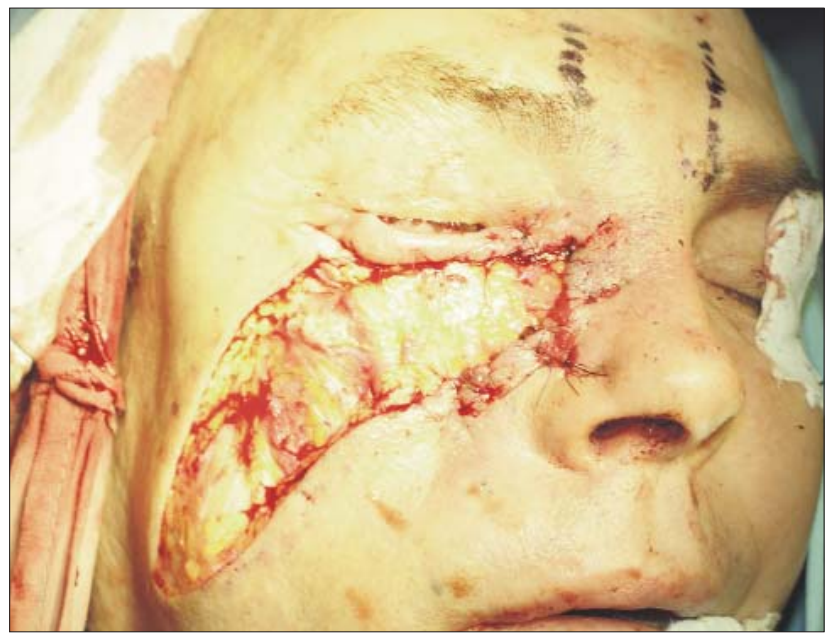

Figure 4 - Final position of the reversed flap

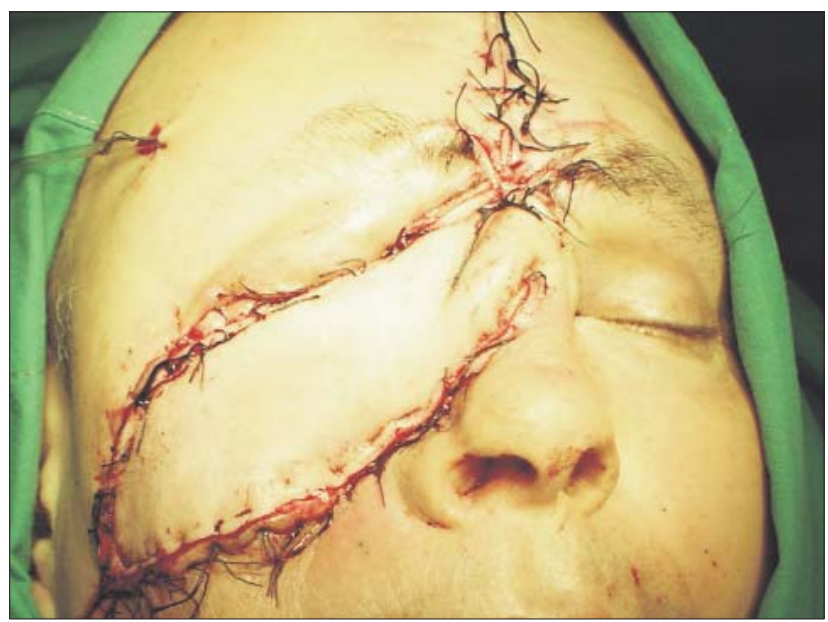

Figure 6 - Final result after the positioning of the forehead flap esthetic results were achieved. No collapse of the paramedian forehead flap was developed. We never encountered sino cutaneous fistulas after the surgery. Three of the 4 patients had underwent previous radiotherapy.

\section{CONCLUSIONS}

We consider the midfacial reversed flap a good alternative in providing a proper mechanical support for the paramedial forehead flap. This method can be used with high rates of success even in patients that had already underwent radiotherapy. No sino cutaneous fistulas were developed. No collapse of the paramedian forehead flap was encountered after surgery. The use of the reversed midfacial flap is an original method that can be used to provide mechanical support for any reconstructive flap in the midfacial region.

\section{REFERENCES}

1. Foster RD, Anthony JP, Singer Ml, Kaplan MJ, Pogrel MA, Mathes SJ. Reconstruction of complex midfacial defects. Plast Reconstr Surg. 1997 May;99(6):1555-65.

2. Resto VA, Chan AW, Deschler DG, Lin DT. Extent of surgery in the management of locally advanced sinonasal malignancies. Head Neck. 2008 Feb;30(2):222-9.

3. Chen AM, Daly ME, Bucci MK, Xia P, Akazawa C, Quivey JM, et al. Carcinomas of the paranasal sinuses and nasal cavity treated with radiotherapy at a single institution over five decades: are we making improvement? Int J Radiat Oncol Biol Phys. 2007 Sep 1;69(1):141-7. Epub 2007 Apr 24.

4. Dulguerov P, Allal AS. Nasal and paranasal sinus carcinoma: how can we continue to make progress? Curr Opin Otolaryngol Head Neck Surg. 2006 Apr;14(2):67-72.

5. Kim GE, Chang SK, Lee SW, Pyo HR, Choi EC, Roh JK, et al. Neoadjuvant chemotherapy and radiation for inoperable carcinoma of the maxillary antrum: a matched-control study. Am J Clin Oncol. 2000 Jun;23(3):301-8.

6. Ranga V, Abagiu N, Panaitescu V, Papahagi P, Ispas A. Anatomia omului Vol. 5 Capul si gatul. Edit. Cerma; 2002. p. 65-88. 